\title{
SMART BLUE CITIES
}

\author{
Aleksander Orłowski ${ }^{1}$ (iD), Edward Szczerbicki² (iD) \\ ${ }^{1}$ Management Department, Faculty of Management and Economics, Gdańsk University of Technology \\ Narutowicza 11/12, 80-233 Gdańsk: Poland \\ aleksander.orlowski@zie.pg.gda.pl \\ ${ }^{2}$ School of Engineering, Faculty of Engineering and Built Environment, University of Newcastle \\ University Drive, Callaghan, NSW 2308, Newcastle: Australia \\ edward.szczerbicki@newcastle.edu.au
}

\begin{abstract}
This paper presents the concept of Smart Cities from the perspective of those located by water, considering if there are more major differences in the way the concept is implemented in coastal cities, as opposed to those located anywhere else. It proves possible to point to such differences, in relation to the three key areas of mobility, the environment and living. Further consideration is given to specific legal and cross-cultural challenges - like excessive tourism and issues of short-term rental - as these appear from the Smart City perspective; and relevant mobility challenges are also addressed. The article further refers to aspects the Smart City and blue growth concepts have in common, as well as to areas in which coordination of the two will be necessary. Ultimately, conclusions are arrived at on the basis of research results for 10 large cities in Poland, the readiness of their city offices to implement the Smart City concept having been the subject of verification.
\end{abstract}

Keywords: blue city, city management, coastal cities, overtourism, short-term rental, smart city.

\section{Introduction}

As cities continue to be home to growing numbers of inhabitants, they are attracting more and more research interest. 3.5 billion people live in urban areas now (i.e. $54 \%$ of the world population), but according to the United Nations that number will have grown to 7 bn by 2045 . As $84 \%$ of the population in North America, and $73 \%$ of that in Europe, lives in cities already, the fastest growth in the statistic in the coming years will be in Asia (UN, 2014). The relevant data are wellknown already, but it is still not the case that all cities are growing. Examples like Detroit (which lost more than half of its inhabitants at a rapid rate) pose major challenges for city managers, but then so do the situations in many cities in Europe, where people move out to the suburbs.

Today's developed cities "are social and technical complex systems characterized by historically unprecedented levels of diversity and temporal and functional integration"(Bettencourt, 2014, p.18). That denotes an ever-greater need for better living conditions in fast-growing cities to be supported. While technology can achieve that on the one hand, processes of city management also need to be pursued, as does participation by city-dwellers in those processes. All of that is manifested at present by the Smart City concept. However, there is also growing specialisation 
of cities, alongside interdependence; to the extent that large cities "are extremely diverse and crucially rely on fine temporal and spatial integration and on faster and more reliable information flows"(Orłowski et al., 2016, p.2).

In this paper the focus is on the possibly specific nature of the Smart City that is located right by water (and is hence a so-called Blue City), with consideration thus being given to how different the process by which this type of city s managed might be. Beyond that, there is here a presentation of how certain Polish cities might try to merge the Smart City and Blue City concepts as they work on strategy, with attention further being paid to the spheres of city functioning that may potentially be of key importance to the relevant coordination effort.

\section{The Smart City}

The Smart City represents what is currently one of the most popular concepts in public management. This makes it surprising to discover that any more precise definition is made difficult by the way the term encompasses such domains as: architecture, technology, environmental protection, Information and Communication Technologies (ICT), management and sociology. In fact, there are numerous definitions to choose from, but these all tend to vary in line with a given author's area of interest. Good examples of the different approaches taken may be offered by the following paragraphs.

Mayor of Bilbao (Spain) I. Azkuna joined Members of the Committee on Digital Knowledge-based Cities in describing the Smart City by focusing mainly on the need for it to utilise ICT (Azkuna, 2012). In turn, the main reason for this was deemed to be for greater effectiveness and productivity to be achieved, along with simultaneous awareness-raising among inhabitants. As seen from Azkuna's perspective, the Smart City approach also denotes investment needing to be made in socio-cultural and human capital, though this was clearly subordinate to investment in ICT.

Another view on the Smart City was presented by G. R. Hollands, for whom three main issues are made apparent by a quote referring to: "the assumptions of the Smart City as a celebratory label, an opinion that the label is more marketing hype than a practical engine for infrastructural change, and the term itself carrying an uncritical, pro-development stance" (Repko \& DeBroux, 2012 , p.18). This led Hollands to respond by asserting that people are the most important element of each Smart City (Hollands, 2008).

W. J. Mitchell (2007), who was responsible for developing the Smart Cities Programme at the Massachusetts Institute of Technology Media Lab compared a Smart City to a fully-formed human organism. In his view, ICT serves as a nervous system ensuring connectivity and interactivity between all elements, and - for that reason - performance of the organism is stable, with problems tending to arise being solved immediately in a way that allows for yet-further and faster development. This concept resembles the previous one in placing major emphasis on the appropriate use of ICT. Without this, the correct operation of the 'organism' would be impossible.

In turn, for S. Ben Letaifa (2015), a city is worthy of the name Smart City when it integrates and synchronises formal leadership and participation of inhabitants. A Smart City is thus as intelligent as it is creative, and its essence is a combination of openness and social innovations both coordinated and monitored by the city itself.

Notwithstanding the lack of a single definition that the above extracts make clear, the Smart City concept has gained formalisation. And, given different perspectives of the above kinds, it 


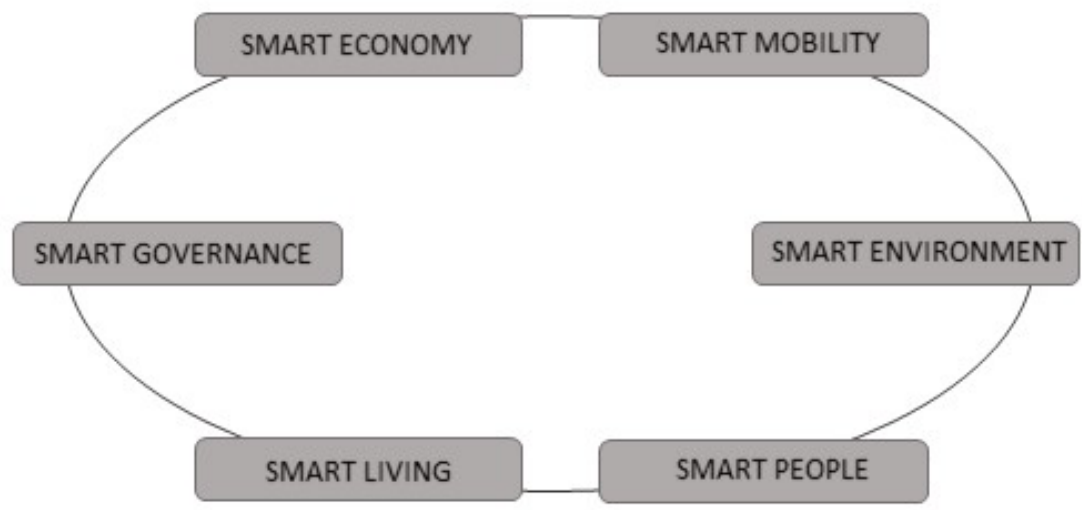

Figure 1. Smart City spheres of interest and involvement Source: VUT (2019).

would seem to be useful to divide matters up into certain formal areas (Fig. 1). The most widespread division of the Smart City is as presented by a team from the Department of Spatial Planning at Vienna University of Technology. In its view, the areas are (Orłowski \& Romanowska, 2019):

- the economy and competitiveness (the Smart Economy),

- transport (Smart Mobility),

- natural resources (the Smart Environment),

- social and human capital (Smart People),

- the standard and quality of life (Smart Living),

- administration and participation (Smart Governance).

Thanks to the identification of the areas listed above it was possible to compare cities in terms of selected aspects, and then to arrive at different classifications. City authorities then have the opportunity to evaluate their own actions, though in practice most use is confined to the marketing perspective. Furthermore, it needs to be mentioned that the list of indicators at times used to order areas includes ones like 'number of sunny days' (VUT, 2019). Does that mean that cities in southern Europe are automatically 'Smarter' than those in the north? Such categories limit the practical usage of rankings.

Any discussion of the background to the Smart City needs to bring in B. Cohen (2015, October 8), who presented a well described concept of three maturity levels of the Smart City that has gained acceptance in the relevant circles (Table 1).

Table 1. The levels to the Smart City

\begin{tabular}{|c|l|}
\hline Type & \multicolumn{1}{c|}{ Description } \\
\hline Smart City 1.0 & $\begin{array}{l}\text { representatives of technology companies turn to the city with a } \\
\text { proposal to implement a specific, ready-made technological solution }\end{array}$ \\
\hline Smart City 2.0 & $\begin{array}{l}\text { cities are the creator of needs, and technology providers - solutions } \\
\text { that are a consequence of these needs }\end{array}$ \\
\hline Smart City 3.0 & $\begin{array}{l}\text { assumption as at the second level (Smart City 2.0), but extended to } \\
\text { the participation of residents in the decision-making process. }\end{array}$ \\
\hline
\end{tabular}

Source: Cohen (2015, October 8). 


\section{The Blue City and blue growth}

As references to Blue Cities are currently made in several different spheres, it is crucial to define precisely what the underlying issues may be. A review of the literature indicates that there are two main spheres in which cities may be termed blue:

1. Blue Cities as cities built in 1950-1980 in Siberia (exemplified by Norilsk, Fig. 2), in which the aim is to explore for and exploit natural resources. These cities have many social problems, are similar from an architectural perspective, and the share the feature that the mining business is the key and central aspect of each such city. Water and location by the water are not then key aspects, and nor are cities of this type normally seen as in any way exemplifying the Smart City concept example. This paper will offer no further consideration of the cities of this type.

2. Blue growth is a term used to describe a long-term strategy whereby t sustainable growth is supported in the marine/maritime sectors. Seas and oceans are regarded as drivers of the European economy, and are seen as having great potential for innovation and growth. This is then the maritime contribution to the achievement of goals set for the Europe 2020 strategy in respect of smart, sustainable and inclusive growth. According to the European Union, the 'blue' economy accounts for some 5.4 million jobs and generates gross added value of almost $€ 500$ bn each year. The EU also presents areas in which growth in the above context is expected. The sectors with high potential for sustainable jobs and growth are taken to be:

- coastal tourism

- marine biotechnology

- aquaculture

- seabed mining

- ocean energy.

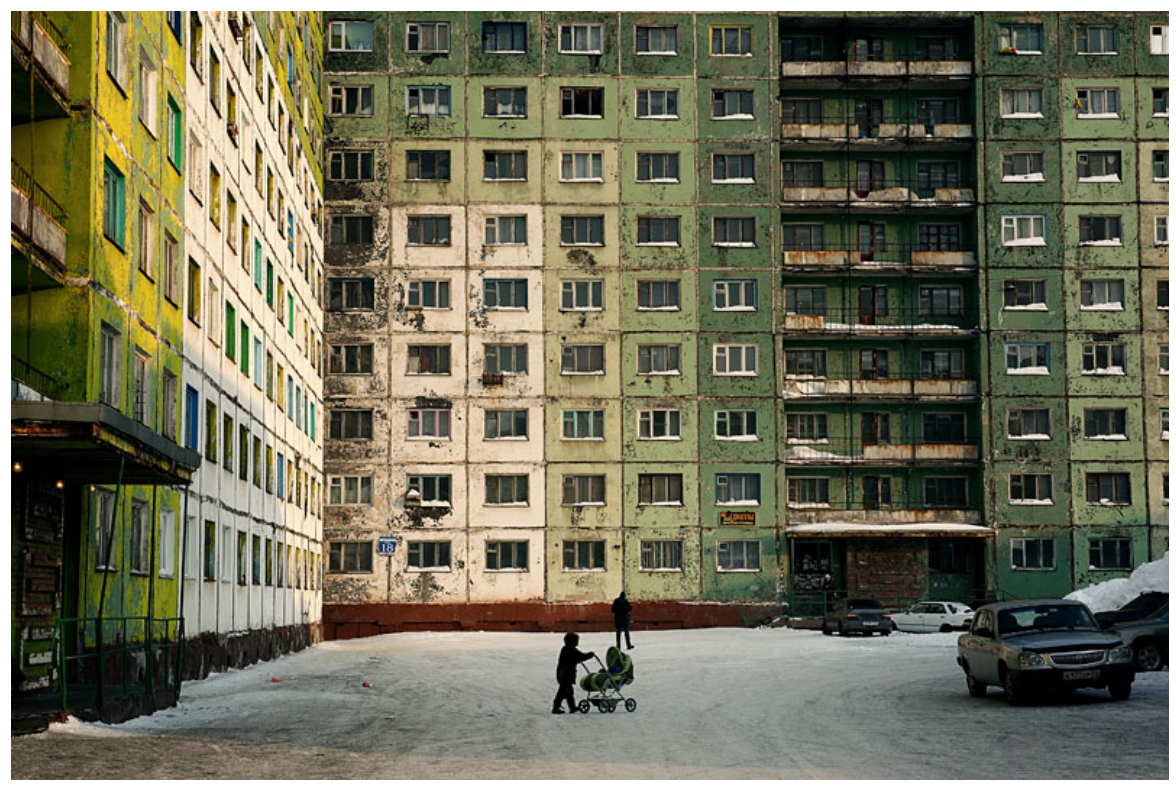

Figure. 2 In the city of Norilsk Source: Żółciak (2019). 
The EU also notes how the essential components (if legal certainty, knowledge and security are to be supplied to the blue economy) would be:

- marine spatial planning to ensure efficient and sustainable management of activities at sea;

- marine knowledge to improve access to information about the sea;

- integrated maritime surveillance offering authorities a fuller picture of events and processes at sea (EC, 2019, November 11).

When discussing Blue Cities it becomes necessary to achieve a more precise presentation of blue growth (which is not a synonym). Blue growth is more than just a question of fisheries, since it extends to the dynamics where the management of maritime and coastal resources is concerned. In the run-up to the World Ocean Summit in June 2015, the Economist Intelligence Unit (Goddard, 2015 , November 2) identified a wide array of 'emerging industries' within blue growth: from pharmaceuticals to eco-tourism to deep-sea mining - with potential interests in the 'ocean economy' (Barbesgaard, 2018).

Blue growth is also seen as "sustainable growth and development emanating from economic activities in the oceans, wetlands and coastal zones, that minimize environmental degradation, biodiversity loss and unsustainable use of living aquatic resources, and maximize economic and social benefits"(FAO, 2015, p.8).

It is also worth referring to F. Sakellariadou and E. Kostopoulou (2015, p.10), for whom marine spatial planning is "a public process for analysing and planning the spatial and temporal distribution of human activities at seam ensuring that they achieve the highest possible levels of efficiency and sustainability, through achievement of economic, social and environmental targets, eliminating conflicts between various users and creating synergies between different activities".

The blue growth concept is strategic, because it turns a negative approach of natural degradation and climate change into a positive one, with a view to new ideas and opportunities with potentially limited impacts on the environment being attracted (Bowen \& Fankhauser, 2011).

Next it would seem necessary to determine what is so unique in Blue Cities, and how those potential features might influence the process of implementing the Smart City concept in them?

\section{The Smart and Blue City}

The concepts of both the Smart City and Blue City are as presented in previous parts of the paper. It is obvious that it does not define the same scientific area, but from the perspective of the city it is crucial to understand what the common parts of both concepts are, with a view to identifying how coastal cities might try to implement the two concepts simultaneously.

First, when it comes to the definition of blue growth (ECORYS) this is take to be "the product of a multi-sector based policy, as it is an economic growth dependent on diverse economic sectors. Its main target is to release and exploit the potential of seas and oceans, therefore it contributes to the objectives of the Europe 2020 strategy for smart, sustainable and inclusive growth" (Sakellariadou \& Kostopoulou, 2015, p.2). The European Union promotes both concepts for cities, and in some documents it is stated that blue growth should be smart (Soma, van der Burg, Hoefnagel, Stuiver \& van der Heide 2018). Nevertheless, no direct relationships have been presented, so it would seem necessary for these to be presented first.

Based on the definitions presented earlier, it seems that it can be said that the Smart City and blue growth are groups having in common a part known as the Blue City. At the same time, the 
Blue City can be seen as a narrower formulation contained in the idea of the Smart City, applying to cities with a specific seaside location.

From a general point of view, there would seem to be three areas common to both concepts. First, both of them concern (may relate) to urban areas and relations within the city (primarily between private and public entities). This means that both concepts are implemented by the same (most often municipal) office and port-area managers. This indicates the need for the implementation of the Smart City and Blue City concepts to be pursued first within the municipal office, then in coordination between that office and port managers. As part of the first phase, this will require both planning and primarily organisational activities (cooperation of relevant departments of municipal offices with each other).

Second, the technological aspect is very important in the definitions of both concepts. As emphasised, in both the Smart City and the Blue City, technology should be used as a tool, not a goal. In line with that, thought needs to be given to the policy needing to be adopted for implemented technological solutions, as well as to whether it is possible to point to common areas for the implementation of technology for Smart and Blue. It is examples of that type of policy that will be presented below.

The third element, extremely important to both concepts, is environmental protection. Under the Smart City approach, there is an entire 'smart environment' sphere relating inter alia to water and air pollution, and energy efficiency. The same is true for blue growth, in which issues of climate change, for example, are a fundamental element of the concept. As Soma et al. (2018, p. 368) note: "The European Union has launched the Blue growth concept as a strategy for economic growth in European seas in the context of climate change, increased scarcity of natural resources, the increased vulnerability of the planet (...)". For this reason, the approach to the issue of environmental protection as one of the foundations to both concepts is convergent. This translates into practical activities in which, for example, water protection in will be an activity within both the Smart City and the Blue City. This requires appropriate organisational coordination (e.g. within a city hall), as was mentioned under the first point.

All three ideas presented above are general in nature, and thus need fleshing out by reference to further practical examples. The breakdown of the Smart Cities concept into categories or topic areas achieved by Vienna University of Technology (and presented in the previous chapter) offers a basis for the identification of dedicated areas in which the Smart City might look different from the Blue City. The three areas ultimately noted were smart mobility, smart living and the smart economy, with this diagnosis reflecting research based on a number of products and technologies already implemented.

\section{Smart mobility}

Given the locations of Blue Cities the use of water as a part of transport systems needs to have particular attention paid to it. However, the circumstance is obviously not particularly unique, as many or most cities are for example located along rivers, with ferries and other forms of on-water transport already therefore forming part of public transport. The Smart City concept within Blue Cities mostly involve other elements of public transport, for example tariff integration. From the technological perspective, more types of autonomous vehicle (e.g. ships) will appear, offering some kind of challenge relating to law. More on this aspect will be presented in the next chapter.

A Smart Blue City might typically deploy water buses - probably using existing water infrastructure to achieve the transport of people by water, between several points of the given city. Viewing that type of bus as a Smart City element of public transport would denote its being connected with other forms (bus, tram and train), but also with mobility shared (using bicycles or in cars). All 
would be included in a single tariff, with one application used to plan the fastest possible journey by various modes. A ship might then be an autonomous form achieving both a reduction in travel costs and an increase in travel safety.

From the legal perspective, what would be denoted here is, say, a water bus operated by a municipal or private company, financed by the city, but operating on water likely managed at the national level or by a port management authority. Equally, from the point of view of the customer, the ticket for the entire journey is purchased via one application with no thought given as to who the operator is, or who owns the infrastructure and at which tier of administration or the private sector.

From the perspective of Polish cities, it might be possible to implement transport of this type in Gdańsk, where water stops are already in existence. But there is no tariff integration, and water buses are basically still taken by tourists only, not within the context of a public transport system. It would be necessary to increase the frequency with which the boats run, to achieve integration with the public-transport tariff and later with other means of transport, and to change the locations of certain (bus or tram) stops, to provide for quick transfers, e.g. bus-boat. The whole effort would of course be preceded by efforts to model passenger movement with account taken of the new means of transport, with main streams of passengers pointed out, and with an indication of precise benefits in areas such as the environment (e.g. through reduced air pollution) and transport (e.g. through reduced traffic along some routes).

The emergence of a new means of transport is likely to contribute to investment activation in some previously-excluded areas of communication, with both (office and residential) development activity encouraged as a knock-on effect. Better transport to elements of maritime industry located above the water (shipyards and port activities) should also be achieved.

\section{Smart living}

From this perspective there are two main areas that characterise Blue Cities and are also important where the Smart City concept is concerned:

- In connection with tourism, it is obvious that cities located hard by water draw tourists, at the same time challenging cities in major ways. In the first place, there may be anxiety regarding over-tourism - as in Barcelona where the statement put bluntly by some is that too many tourists visit the city (as set against the number of inhabitants). However, the problem might relate less to numbers of tourists and more to phenomena associated with their presence en masse. Poland's city of Gdańsk (Orłowski, 2019) offers an example whereby the prices of flats in the city rise on account of their being purchased and then rented (short-term via AirBnB or booking. com). Here we note how new technologies (normally presented as the very essence of the Smart City) offer as much of a challenge as an opportunity. Further down the line, other negative aspects for the city (or indeed a city) are that the part associated most with tourism (often in fact located close to water) has fewer and fewer inhabitants and becomes more and more dedicated to serving the visitor (with fewer and fewer shops and services for any remaining residents that there may be, and more and more bars, restaurants and services associated directly with tourists). Then there is the way in which price rises are not confined to tourism-related parts of the city, as inhabitants' movements to other districts ensure increased demand - and prices - in those areas as well. In general, then, a city of the above profile finds it increasingly difficult to acquire new inhabitants, especially in comparison with cities less attractive to tourists whose costs of housing remain lower. Ultimately, this can affect the ability to attract new investors as well, given the need for these to hire employees. 
- In connection with housing on or by water, Blue Cities have issues with houseboats, flats in the immediate vicinity of the sea, even new islands. A case again relating to the Polish city of Gdańsk saw attempts made to develop houseboats and the phenomenon of houseboat residence. More than 10 years ago, first interested parties sought to make their homes in Gdańsk city centre, by means of houseboats. However, legal conditions present at the outset entirely prevented approaches of this kind (with problems inter alia concerning utilities, the collection of waste and the lack of a permanent home address). Today, these basic problems have in most cases been solved, though the matter of the coordination of this type of development remains and may in fact be growing in prominence. The city adopts a plan of spatial development for water areas under the management of the port authority. Considering the environmental issues present in both the Smart City and Blue Growth concepts, such dwellings should become more energy efficient, generate less waste, and at the same time be planned in places where the functioning of the city more widely is adapted to (given the need for the latter to supply media and ensure communication accessibility), and port activities are not impeded. Once again, there is the aforementioned need for coordination of planning processes between institutions, in line with the possibilities the technology developed by business are able to provide.

\section{Smart economy}

The smart economy relates to areas of key importance for the industry present in Blue Cities. In most relevant cases, key businesses are in tourism, fishing and offshore industries. Increasingly, however, new technologies and sectors may be involved, like pharmaceuticals (based on sea-life) or deep-sea mining. And, while tourism might be important in inland cities, the other areas referred mostly cannot be, by definition. Equally, it is by no means the case that the above are the only types of business present in Blue Cities, but they are characteristic for localities of that type. Thinking about the Smart City denotes a necessity that there be both the (properly-qualified) people, and the (R\&D) technology needed for businesses of the above type to develop and thrive, with this naturally also linking up with the education system.

From the point of view of the Blue City, it is crucial to indicate a wider context to the impact on economic development both more locally and regionally. In Poland, the planned construction of the Central Port in Gdańsk is more than just a matter of benefits accruing to the port itself (increased turnover and product volume) or indeed the Polish state (which obtains higher tax revenues). Rather, a recently-signed agreement between the authorities responsible for managing the airport and the seaport points to synergies developing, with the new port for example being a place where passengers can readily access cruise ships, while their crews change over. Good air communication is needed for that, with new passengers for the airport generated (along with higher revenues) as revenues for the seaport also rise, and as (yet more) new tourists are by the way attracted to the city itself. The development of a new industry related to initial servicing of cruise ships is also to be anticipated. At the same time, from the Smart City point of view, the use of new technological solutions will allow, for example, for baggage checked in at a New York airport to be collected directly on board a cruise ship in the port of Gdańsk (the baggage travelling the New York-Warsaw-Gdańsk route, and then from airport to seaport). This will require both logistical coordination (ICT) and appropriate legal (e.g. customs-related) conditioning. 


\section{The authors' own research findings}

The three areas of interest presented in the previous section were not offered as unusual challenges for cities. But key questions arising relate to responsibility/accountability for the implementation and coordination of projects of the Smart City type in Blue Cities. In general, city hall is seen to be the institution responsible for most Smart City projects, and hence the key player in the implementation and pursuit of the concept as a whole,as research by A. Orłowski (2019) makes clear. When new developments are located on or close to water, there are other important players like a maritime office or seaport management authority, mostly independent of City Hall. Where there is more than one party needing to coordinate processes in a city (and more than one interest that may differ), the consequence is the complication of projects, which will tend to last longer, require more paperwork, and be more difficult to decide on officially in the first place.

A second key issue needing to be mentioned here relates to the shaping of changes (like those presented in the previous section) in such a way that we go beyond gadgets and achieve genuinely useful tools that improve inhabitants' lives. Most current technological projects are expensive, so how to select the ones most effective from inhabitants' points of view?

As challenges for Smart Blue Cities are addressed and presented, it is worth referring to research (Orłowski, 2019) carried out in the area between major city halls in Poland and consortia of such leading ICT companies as IBM and Cisco. An answer was being sought to a question as to why major cities are not so obviously seeking the ICT systems the companies develop. Initial research in this area had the four main goals of

- determining Polish municipal offices' level of interest in implementing Smart City systems;

- assessing possibilities for the above systems to be implemented in the said offices in Poland;

- building recommendations for suppliers of ICT systems;

- recognising cities' strategies as regards cooperation with the above suppliers.

Following the initial research it was concluded that city hall representatives are also interested in finding how to communicate successfully with companies to receive the type of product they need. In line with that, the key research was done with ten large cities in Poland (of 100,000 inhabitants and more). A combined quantitative and qualitative approach was taken, with direct interviews (of 2 hours on average) run with the following key city hall representatives:

- the President of the Union of Polish Cities and Mayor of Gliwice

- the President of Rybnik

- the Mayor of Toruń

- the Vice President of Rzeszów

- the Secretary of the City of Bialystok

- the Director of the IT Department at Warsaw City Hall

- the Advisor to the Mayor of Kraków on the Smart City and e-administration

- the Advisor to the President of Lublin on the Smart City

- the Chief Specialist in the Open Data team at the City Hall in Gdańsk.

- The Chief Smart City Specialist and Director at Poznań City Hall.

The main result of the research was a concept and model in respect of the Process Readiness of a Municipal Office to reach the Smart City (for all details see Orłowski, 2019).

What is crucial from the perspective of this paper is awareness of any significant differences arising from the study that might pertain between Blue Cities and cities located inland, when it comes to implementation of the Smart City concept. However, among the cities investigated only 
one (Gdańsk) is by the sea and therefore suitable for terming a Blue City. This leaves the results presented here as nothing more than a starting point for further research. It would next be worth investigating other cities located by the water, such as Szczecin and Gdynia.

Nevertheless, in line with the research results it is possible to point to certain aspects special to the city of Gdańsk. First, representatives of two other cities discussing the variables important in describing the readiness of a City Hall to attain Smart City status, claimed that cities located by the sea lack major problems with air pollution because of their location (and strong wind). Second while the City Hall officials were being researched, they claimed that a Smart City readiness model must use a variable presenting the experience of the city in its joint work between the City Hall, the Maritime Office and the Port Authority. Most key projects fall within the areas of interest of at least two of the institutions presented, and it is a must for that work to be coordinated (with it for example being decided and clear which institution is to set standards).

A few other minor aspects were also referred to, but these do not look important from the general perspective of Blue Cities. So do these findings justify an assertion that Blue Cities require efforts different from Smart Cities? Some local differences were observed (as noted above), but similar differences might also be observed when the comparison is with cities in which mining is a key sector present. There too, the city hall has other organisations (the mine itself and some mining offices) with which it must cooperate to be effective. But that also means that Blue Cities are not particularly special when it comes to the implementation of Smart City projects, having cooperation and legal problems similar to those in cities located quite differently.

\section{Summary and conclusions}

Blue Cities constitute cities of a special type, given their locations; and this is seen to be connected with management challenges. The main goal of this paper and the new work it details has been to present the relationship between the Blue City and Smart City concepts, in particular where implementation is concerned. Should Smart City implementation in Blue Cities be different, and - if yes - in which areas?

The paper was in fact in a position to present three such key areas (smart mobility, smart living and the smart economy) in which Smart City projects might indeed look different in Blue Cities. The most important difference centred on the law, given that regulations in this case originate with several different, key players in cities of the type under investigation (i.e. the city halls, the Maritime Office and the Port Authority), and are to observed in all three of the key areas identified.

The aforementioned new research carried out by a co-author of the article then gained presentation, with this having been carried out in both inland cities and a Blue City. Key findings here related to the fact that the Smart City goes beyond technology pure and simple. Useful though this may indeed be, a city needs more than just gadget, and this is all the more so with Blue Cities, whose locations demand specific technologies. It is also important to mention that, because technology is changing so very quickly, key points are awareness of where it is necessary, and what it is necessary for.

Identified as very much needed is the strategic-level coordination of efforts to achieve the Smart City in the Blue City. The coordination process can be local or central, but local coordination via a municipal office can be difficult (for reasons highlighted in the article), given the ownership and management structure vis-à-vis ports and maritime areas. Coordination at local level may thus take the form of Smart Specializations created for a given region. Poland's pomorskie voivodeship (Pomerania) has its Smart Port Smart City Specialization (in which one of this paper's authors is a 
participant). However, the effectiveness of such a legal creation is disputable, leaving it plausible to believe that the most effective cooperation will pertain between interested parties (as seems to be the case between the Airport and the Sea Port in Gdańsk, as the main body of this article notes.

From the Polish point of view, three large urban centres aspiring to be Smart Blue Cities can be identified. These are Szczecin, Gdynia and Gdańsk. However, as things stand today, none of these can yet be considered to have achieved the status. However, there are certain fields of intensive current activity, mainly tourism and transport. The main current challenges for the cities in question is the implementation of the Smart City concept along with blue growth activities. Coordination of these activities only be the next step, and will not least entail changes in relation to the law, as is noted above.

To fully illustrate the challenges facing Smart Blue Cities, it would be necessary to research the coordination of investment projects and strategic documents applying to areas located by the water in the three cities referred to above. There is currently only partial knowledge of this, mainly in regard to the pursuit of the Smart City concept in city offices. Nevertheless, an indication of relevant good practices and specific restrictions would offer a good starting point for the further discussion of plans and precise areas of implementation where the Smart Blue City is concerned. As is noted by the authors (and by Soma et al., 2018), both concepts assign key status to technology and its impacts (not least on the environment). Much less is said about the social dimension to change, and if this is not addressed, strategies will become nothing more than technology-oriented. A second important research area is thus signalled here. Smart space seems to appear more often in the literature (e.g. Bach-Głowinska, 2014), so that aspect should also be tackled in future research.

Ultimately, where the Smart City perspective is concerned, the locations of Blue Cities should be seen as an asset and a challenge simultaneously, as the article notes - not least in regard to relevant regulations. However, the most important question in many respects has concerned whether Blue Cities are really so unique from the Smart City point of view that they require dedicated strategies. Our research shows that Blue Cities are indeed different in some important respects, but then so are cities of other types (e.g. those in mining regions). Future research in the areas indicated above would be needed to fully quantify and evaluate the differences in question, and would likely be a matter for special organisational units.

\section{References}

Azkuna, I. (2012). Smart Cities Study: International study on the situation of ICT, innovation and Knowledge in cities. The Committee of Digital and Knowledge-based Cities of UCLG. Bilbao: The Committee of Digital and Knowledge-based Cities of UCLG. Retrieved from http://www.uclg-digitalcities.org/ app/uploads/2015/06/en_smartcitiesstudy.pdf

Bach-Głowinska, J. (2014). Inteligentna przestrzeń. Warsaw: Wolters Kluwer.

Barbesgaard, M. (2018). Blue growth: savior or ocean grabbing? The Journal of Peasant Studies, 45(1), 130-149. https://doi.org/10.1080/03066150.2017.1377186

Ben Letaifa, S. (2015). How to strategize smart city: Revealing the SMART model. Journal of Business Research, 68(7), 1414-1419. https://doi.org/10.1016/j.jbusres.2015.01.024

Bettencourt, L. (2014). The Uses of Big Data in Cities. Big Data, 2(1), 12-22. https://doi.org/10.1089/ big.2013.0042

Bowen, A., \& Fankhauser, S. (2011). The green growth narrative: paradigm shift or just spin? Global Environmental Change, 21(4), 1157-1159. https://doi.org/10.1016/j.gloenvcha.2011.07.007

Cohen, B. (2015, October 8). The 3 Generations of Smart City. Fast Company. Retrieved from https:// www.fastcompany.com/3047795/the-3-generations-of-smart-City 
EC (2019, November 11). Blue Growth. Retrieved from https://ec.europa.eu/maritimeaffairs/policy/ blue_growth_en

FAO (2015). Oceans and sustainable development: integration of the three dimensions of sustainable development, namely environmental, social and economic. Draft Resolution A/69/L.29. Secretary-General on Oceans and the Law of the Sea. Retrieved from http://www.un.org/depts/los/general_assembly/contributions_2015/FAO.pdf

Hollands G. R. (2008). Will the real smart city please stand up? City, 12(3), 303-320. https://doi. org/10.1080/13604810802479126

Mitchell W., J. (2007). Intelligent cities. e-Journal on the Knowledge Society, 5. Retrieved from http:// www.uoc.edu/uocpapers/5/dt/eng/mitchell.pdf

Orłowski, A., \& Romanowska, P. (2019). Smart Cities Concept: Smart Mobility Indicator. Cybernetics and Systems, 50(2), 118-131. https://doi.org/10.1080/01969722.2019.1565120

Orłowski, A. (2019). Model gotowości procesowej urzędu miejskiego dojścia do Smart City. Warsaw: CeDeWu.

Orłowski, C., Ziółkowski, A., Orłowski, A., Kapłański, P., Sitek, T., \& Pokrzywnicki, W. (2016). High-Level Model for the Design of KPIs for Smart Cities Systems. In N., Nguyen, R., Kowalczyk, C., Orłowski \& A. Ziółkowski A. (Eds.). Transactions on Computational Collective Intelligence XXV. Lecture Notes in Computer Science (vol. 9990, pp. 1-14). Berlin, Heidelberg: Springer. https://doi.org/10.1007/9783-662-53580-6_1

Repko, J., \& DeBroux, S. (2012). Smart Cities Literature Review and Analysis. IMT, 598, pp. 18.

Sakellariadou, F., \& Kostopoulou, E. (2015). Marine ecotourism from the perspective of blue growth. Conference Paper, 7th iCOnEc Conference Competitiveness and Stability in the Knowledge-based Economy, pp. 10.

Soma, K., van der Burg, S., Hoefnagel, E., Stuiver, M., \& van der Heide, M. (2018). Social innovation - A future pathway for Blue growth? Marine Policy, 87, 363-370. https://doi.org/10.1016/j.marpol.2017.10.008

Goddard, C. (2015, November 2). The ocean business: The rise of rhetoric of the blue economy. The Economist. Retrieved from http://www.theworldin.com/article/10625/ocean-business

UN (2014). World Urbanization Prospects. The 2014 Revision. Department of Economic and Social Affairs.

VUT (2019). Vienna University of Technology. Retrieved from http://www.smart-cities.eu /?cid=2\&ver=4,21.11.2019

Żółciak, A. (2019). Życie za kołem podbiegunowym - Norylsk na zdjęciach Eleny Czernyszowej. Digital Camera Polska. Retrieved on November 16, 2019 from https://digitalcamerapolska.pl/inspiracje/1085-zycie-za-kolem-podbiegunowym-norylsk-na-zdjeciach-eleny-czernyszowej 